\title{
I-Candies: Supporting Semi-formal Communication in a Coffee Corner
}

\author{
Khairun Fachry ${ }^{1, *}$, Ingrid Mulder ${ }^{2}$, Henk Eertink$^{2}$, and Hans Zandbelt ${ }^{2}$ \\ ${ }^{1}$ User System Interaction \\ Eindhoven University of Technology \\ Eindhoven, NL \\ Archives and Information Science, University of Amsterdam, Amsterdam, NL \\ k.n.fachry@uva.nl \\ ${ }^{2}$ Telematica Instituut \\ Brouwerijstraat 1, Enschede, NL \\ \{ingrid.mulder, henk.eertink, hans.zandbelt\}@telin.nl
}

\begin{abstract}
This paper describes the development of a multi-user interactive display in the coffee corner that makes the office workers aware of events happening within the company aiming to stimulate social interaction. New input devices, i-Candies (fake candies integrated with RFID tags) are used as multiuser input devices for explicit interactions with the display. The interactive display and i-Candies have been deployed and tested within the office environment.
\end{abstract}

Keywords: Design, Tangible User Interface, Context-aware System.

\section{Introduction}

In today's knowledge-intensive world, knowledge workers face more and more complex information. However, much can be achieved by presenting the right information at the right place for the knowledge workers. In this paper, we describe a service that presents information of interest to knowledge workers in a coffee corner, while they are having breaks. As a first step in a user-centered design process, we observed knowledge workers in order to understand their behaviors in an office coffee corner. The observations confirmed that the office workers tend to perform informal and semi-formal communication while they are in the coffee corner. It is in keeping with the finding of Whittaker et al. [10] that a shared physical environment promotes informal social communication. From those findings, we designed a multi-user interactive display in the coffee corner that makes the office workers aware of events that are happening within the company and of general events and news. Furthermore, Agamanolis [1] found that half the battle in designing an interactive situated or public display is designing how the display will invite that interaction. In keeping with Churchill et al. [3] users need constant encouragement and demonstration to interact with the interactive public display. This project aims to entice office workers' curiosity by: on the one hand, re-using and

\footnotetext{
* Corresponding Author.
} 
automatically refreshing company-related information, and on the other hand by introducing a new way of interaction input device, the i-Candies.

\section{A Sweet Dish for the Coffee Corner}

In order to attract office workers an ideal company awareness system should show daily updated information. Both company-specific content that reuses existing information and content of general interest were combined. Consequently, the system remained interesting and useful for the employees. In this way, we enticed the office workers to check for new content on the display. On this display, the following categories of information were presented:

1. Company Announcements are taken from the internal knowledge management system.

2. Latest Publications presents the most recent publications of the company.

3. Where are Our Colleagues presents the location of their colleagues.

4. What is Happening in the World presents the international news.

5. How is the weather? presents the weather forecast.

From the observation study, we learned that input devices should be easy to use and fun to use. Taken these requirements into account, a sweet dish inspired us to symbolize the social interaction of drinking coffee resulting in the design of i-Candies in combination with an i-Bowl as input devices. The i-Candies have been designed in the form of colorful candies to make the interaction playful and interesting. The metaphors of the i-Candies and the i-Bowl match the environment of the coffee corner, as there are cups and tea bags around the table. More importantly, the physical form of the I-Candies raises curiosity of the office worker. The i-Candies were made of foam and were integrated with RFID tags. The i-Bowl is a small bowl that with an integrated RFID reader. Pictures of all i-Candies are presented on the display as navigational cues. The user chooses the content she wants to see by placing an iCandy on the i-Bowl. The display then presents the requested information, updates its screen and presents the next possible presentation. All i-Candies are on the table which enables users to easily choose and pick i-Candies and stimulates the involvement of multiple users. Still, one i-Candy can be placed inside the i-Bowl, which facilitates a social way for interaction allowing a group of people interaction with the system simultaneously.
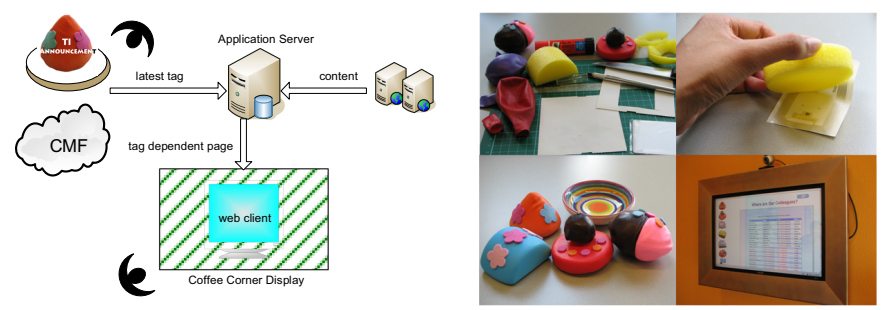

Fig. 1. The system architecture and making of the i-Candies 
The prototype has been implemented as a web-based application running on the coffee corner display. The context information needed by the coffee corner system is provided by the the RFID identification. The RFID identification is facilitated by the CMF [8]. CMF provides the attributes location, time, and RFID tag number and stores them in a database of the application server. New content is provided if a new RFID tag is detected, using a polling mechanism. It will detect the tag number and retrieves the page associates with the tag number.

In keeping with Mark Weiser's vision of ubiquitous computing where a world in which computational services can be naturally and "invisibly" integrated into our physical environment [9], the i-Candies and the i-Bowl are used to illustrate how everyday objects related to drinking coffee can be part of a context-aware coffee environment. Computers usually have very well-defined input interfaces i.e. mouse and keyboard. In the current project, we therefore, focused on making this input interface "blended" in the environment and more playful for the users. The interaction tags of candies is a part of the evolving line of tangible interface work $[2,6]$, which determined to investigate interactive techniques for input devices. Candies are something that is consumed during informal meetings could make people feel sweet and rejuvenated during the coffee break. The nature of a candy as something that is sweet is being replicated to human feelings. In our system, the displayed information comprises interesting news and company information that make people think and smile. Also the candies are being shared by people as the nature of the information that is presented in the coffee corner. The information that the i-Candies control has been studied before. The Notification Collage [5] portrays items posted by users within a workgroup by creating a collage, rather than a single item at a time. Placing one i-Candy at a time presents a single item which provides content that is more easily digestible for the users. Furthermore, work on designing technology-rich spaces to attract user interaction and enhance human-to-human sociability has been a promising research. The GROUPCAST [7] and Intellibadge systems [4] are applications that present information in a large display in a shared area. In the current project we elaborated upon these ideas by combining information with 'sweet' input devices and providing ways to make the passersby curious about the system.

\section{Discussion and Conclusions}

To evaluate the experience of the office workers while interacting with the system, we tested the system in a real office coffee corner. Based on user interviews as well as raw usage data, it can be concluded that the system entices people to interact with it. Interview results also indicated that the users like the metaphor and the game-like interaction of the candies. More importantly, users like the continuously updated content. The content made them more aware of their surrounding activities in an easier and faster way. Furthermore, the system usage was logged to count the number of i-Candies placed on the i-Bowl. Even though, after some time, the users get used to the i-Candies, usage of the system did not decrease drastically. This might be due to the dynamic content of the system. Occasional heavy usage of the system was due to guests visiting the company. As first-time users, their curiosity to try out the system was much higher than the frequent users of the system. Another interesting result is 
that even after the evaluation period, the system is still in use in the office. The users gave positive feedback and proposed many ideas of applications that the company awareness system could be tapped into. Interestingly, by showing the recently published articles in the coffee corner, colleagues were encouraged to archive their work in line with administrative rules without feeling compelled to do. Another not trivial result of the i-Candies was that it influenced the interaction among the research engineers in a positive way. Mainly because of the fact that our prototype derived upon existing ideas, and relies upon existing work done by colleagues on contextaware systems, our implementation in the available coffee corner was established in many related projects and therefore also influenced many colleagues' work. The positive effect of playing with the system was that they get more insight in their contributions and their perspectives, and consequently, results in constructive collaborative design. A striking example is that it quickened the debugging process, and definitely contributed to good working relationships among the involved designers.

\section{References}

1. Agamanolis, S.: Designing Displays for Human Connectedness. In: O’Hara, K., Perry, M., Churchill, E., Russell, D. (eds.) Public and situated displays: Social and interactional aspects of shared display technologies, Kluwer, Dordrecht (2003)

2. Camarata, K., Do, E.Y.-L., Johnson, B.D., and Gross, M.D.: Navigational blocks: Navigating information space with tangible media. In: Proceedings of the International Conference on Intelligent User Interfaces. San Francisco, USA, January 2002, pp. 31-38 (2002)

3. Churchill, E.F., Nelson, L., Denoue, L., Helfman, J., Murphy, P.: Interactive systems in public places: Sharing multimedia content with interactive public displays: A case study. In: Proceedings of the 2004 Conference on Designing Interactive Systems (DIS2004), Cambridge, MA, pp. 7-16 (August 2004)

4. Cox, D., Kindratenko, V., Pointer, D.: IntelliBadge ${ }^{\mathrm{TM}}$ : Towards Providing Location-Aware Value-Added Services at Academic Conferences. In: Dey, A.K., Schmidt, A., McCarthy, J.F. (eds.) UbiComp 2003. LNCS, vol. 2864, pp. 264-280. Springer, Heidelberg (2003)

5. Greenberg, S., Rounding, M.: The Notification Collage. In: Proceedings of CHI 2001, pp. 514-521. ACM Press, New York (2001)

6. Ishii, H., Mazalek, A., Lee, J.: Bottles as a Minimal Interface to Access Digital Information. In: Extended Abstracts of CHI 2001, pp. 187-188 (2001)

7. McCarthy, J.F., Costa, T.J., Liongosari, E.S.: UNICAST, OUTCAST \& GROUPCAST: Three Steps toward Ubiquitous Peripheral Displays. In: Abowd, G.D., Brumitt, B., Shafer, S. (eds.) Ubicomp 2001: Ubiquitous Computing. LNCS, vol. 2201, pp. 332-345. Springer, Heidelberg (2001)

8. van Sinderen, M.J., van Halteren, A.T., Wegdam, M., Meeuwissen, H.B., Eertink, E.H.: Supporting context-aware mobile applications: an infrastructure approach. IEEE Communications Magazine 44(9), 96-104

9. Weiser, M.: The Computer for the $21^{\text {st }}$ Century, in Scientific American 265(3), 94-104 (1991)

10. Whittaker, S., Frohlich, D., Daly-Jones, O.: Informal communication: What is it like and how might we support it? In: Proceedings of CHI 1994 (1994) 